\title{
Line of Sight Implementation for Game Platformer
}

\author{
Andika Eko Kristanto ${ }^{* 1}$, Lailatul Husniah ${ }^{2}$, Ali Sofyan Kholimi ${ }^{3}$ \\ 1,2,3Teknik Informatika/Universitas Muhammadiyah Malang \\ an.dikkatta@webmail.umm.ac.id ${ }^{* 1}$, husniah@umm.ac.id ${ }^{2}$, kholimi@umm.ac.id ${ }^{3}$
}

\begin{abstract}
Traditional weapon is one of cultural heritage from our ancestors in Indonesia. While it can be noted that the popularity of less traditional weapons in the know by many people because it is losing popularity with weapons from other countries. But now there are some people who make use of media technology to preserve the traditional cultures ranging from custom homes, traditional clothing and also a traditional weapon from every province in Indonesia. Be aware that in Indonesia traditional weapon there are diverse, but some provinces have the same traditional weapons it can because the province having the same family or experience the separation area. So, on the development level, authors will make the concept of continuous Boss for some provinces that have same traditional weapons. In addition to developing a level of the game, the author also applied line of sight method on the boss enemy.
\end{abstract}

Keywords: Android 2d Game, Action Adventure Platformer, Mystical Weapons of Nusantara Game, Line of Sight

\section{Introduction.}

Game Mystical Weapon of Nusantara [1] is a game aimed to invite users to know and learn a variety of traditional weapons back from 34 provinces in Indonesia using android smartphone to run the game [2]. But in this late research only 2 weapons has been introduced and created the level. So, based on that issue the author aims to continue research on game Mystical Weapon of Nusantara, the writer will do the addition of some levels and other features.

$\mathrm{Be}$ aware that in Indonesia there are a variety of traditional weapons, but some provinces have the same traditional weapon, this can be due to the province that has the same culture or experience the separation of province area. So, on the development level authors will make the concept of continuous Boss for some provinces that have same traditional weapons. Because traditional weapons obtained on some of the same level, then the author will add either a substitute gift of traditional clothing or equipment from the shield used on traditional dance.

In addition to developing a level of the game, the author also applied the method of line of sight on the boss. This method is in the form of artificial intelligence is applied to the boss. This method is used to add vision to Enemy Boss, so the Enemy Boss can determine the position of the player as Boss viewed towards the player [3]. Besides the addition of the method line of sight is used to find out that the player is in a State of visible enemy boss or not when it enters the range of the enemy, suppose that player enters the attack range from boss but was under an area so the boss can't see the player then the boss will not launch an attack [4].

Based on the above exposure is expected with the development of game Mystical Weapon of Nusantara can forward the goal of this game can gives users insight towards traditional weapons that existed in Indonesia.

\section{Research Method}

Every game [5] made sure has an artificial intelligence, artificial Intelligence (Al) is a branch of computer science that studies and develops machines, programs, or robot that can behave like human beings. In the world of game Al can be said to be the driving force of the non-playable character (NPC) that can respond to the actions of the player. Figure 1 can be seen model Al game is divided into 3 parts namely movement which handle the movement of NPC, decision making will handle the decision it make after meet some condition from world or character player that have interaction with the NPC, and strategy will handle some group of NPC simultaneously i.e. the movement of some troops enemy after detecting character player movement. 


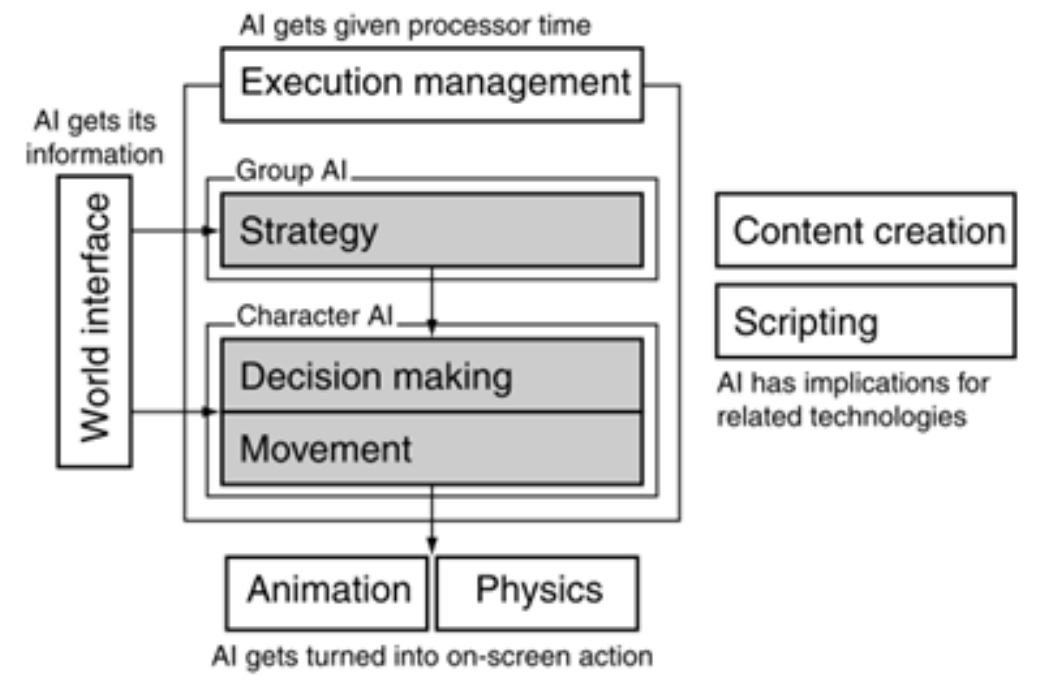

Figure 1. Illustration of Al Game Model [3]

Autonomous Character or NPC will take the information from the data of the game, after that it will determine action based on the information received and run the action in accordance with the behavior it assigned [3]. In Figure 2 the autonomous behavior of NPC's own Hierarchy divided into three layers, namely action selection, steering and locomotion [6].

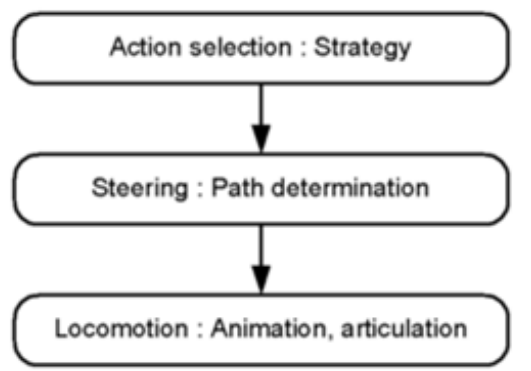

Figure 2. Hierarchy Autonomous Behavior of NPC[6]

Collider2d is a component that is used to define the shape of a $2 \mathrm{D}$ object, components can also be used to detect a friction/collision with other objects besides components can also be used to start an event when there are other objects that enter, colliding or touching the object collider2d[7]. In this study using a Circle Collider2d [8] that is one form of Collider2d.

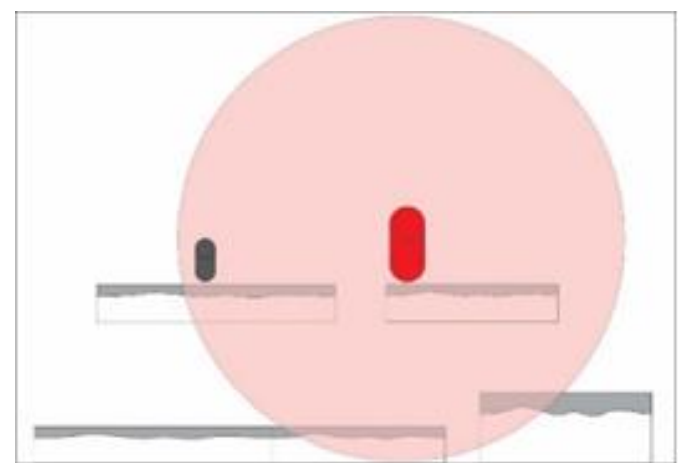

Figure 3. Implementation Circle Collider2d

In Figure 3 being the Red capsules are the enemy boss then the red circle is the Circle Collider2d which serves to detect the player when it enters the red area. Ray cast is [9] is a component that is used to detect objects or with the collider. The workings of his own like firing 
lasers ray cast towards specified objects that are exposed to the laser will be detected and reported back.

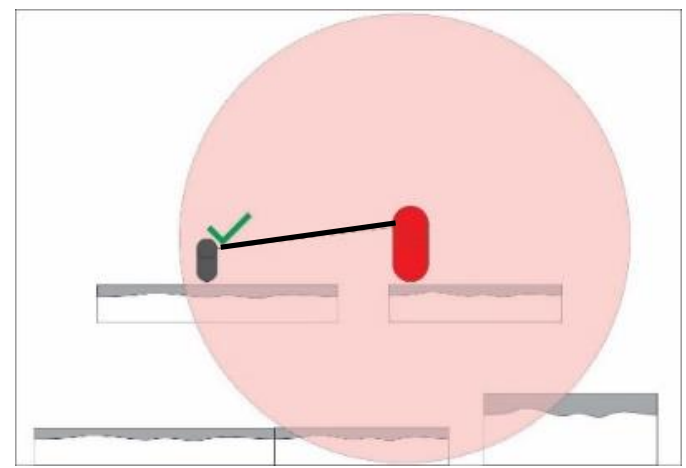

Figurer 4. Implementing Ray Cast

In Figure 4, before applying the method of line of sight, the initial phases of this research was the development level. On this research will be developed as many as three additional levels from the island of Kalimantan.

This research will use a picture where there are images at the pixel color representing each asset will be used. So, each pixel in the image will be represented the asset in the game, each asset will be represented by a different color. For its implementation can be seen in Figure 5 .

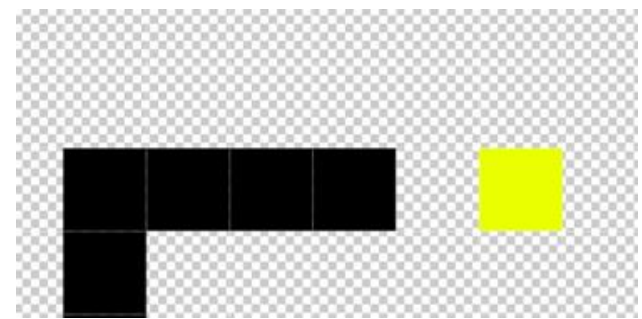

(a)

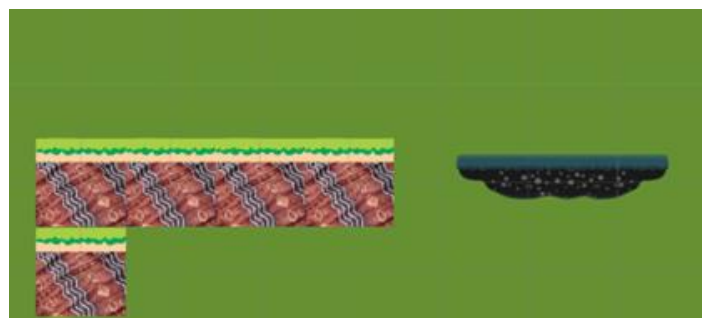

(b)

Figure 5. (a) Start Image (b) After Conversion in Game

In Figure $5(A)$ there is a pixel color black and yellow, each pixel will be replaced by the asset to be used. On the pixels with the color black will be replaced into asset tile and the yellow color will be replaced into asset moving platform. How does each pixel color will be replaced with the appropriate asset can be seen in Figure 6.

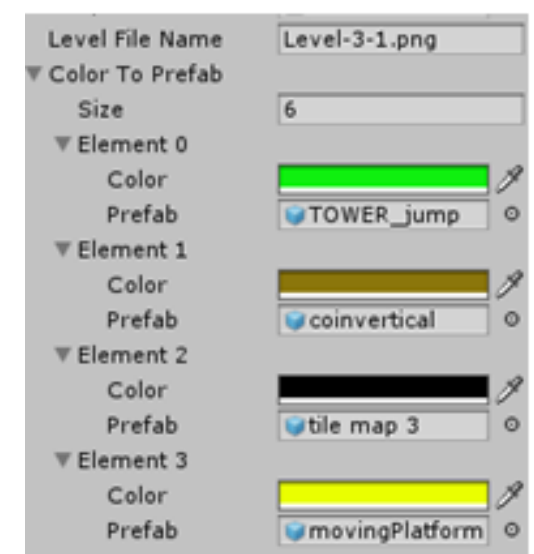

Figure 6. The Display to Adjust the Pixel Color with Asset

The next step is the application of the method line of sight on a boss enemy, before we would make a diagram of finite state machines (FSM) for boss. there are three remarks on the connecting conditions i.e. "enter collider and not seen", "enter Collider and seen ", and" enter 
collider behind boss". For a description of "enter collider and not seen" state run is ignored, because the player is at the range attack Boss but not seen directly by the Boss. For a description of "enter collider and seen" will be heading on the conditions of "Special Attack", attacks that target the player directly will be launched when the player enters the range attack of the Boss and look directly by the Boss or the player in the condition is not deterred. Then the caption "enter collider behind boss" would head the state turn, on this state the Boss will be reversible when the player sits behind the Boss at the time entered a range Boss enemy attacks. For 2 other state i.e. basic attack and state die, state die will run when HP (Health Bar) Boss reach 0. Diagrams can be seen in Figure 7.

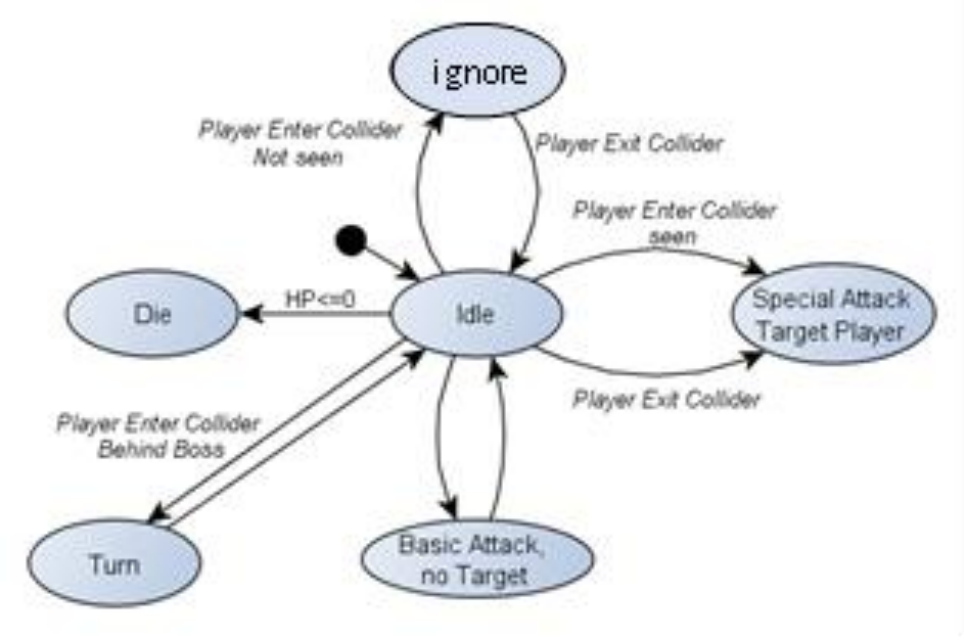

Figure 7. The Design of Al on a Boss Enemy Using FSM

The next stage is the application of line of sight on a boss enemy, the first is the application of circle collider2d on a boss enemy as in Figure $8(A)$ and the application of the tag "player" on characters such as in Figure 8 (B). Then the next step is the application of ray cast by invoking the "sight start" at the boss enemy and "sight end" at the character player.

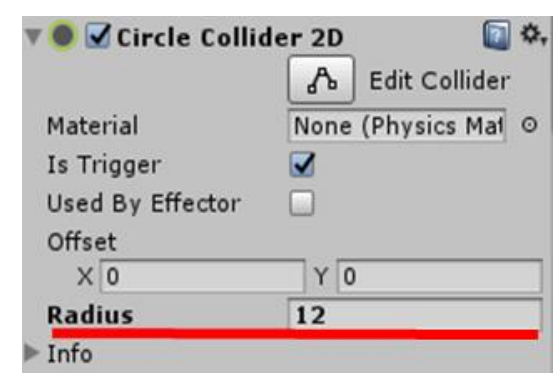

(a)

\begin{tabular}{|c|c|}
\hline Sight Start & Sightstart (Transform) \\
\hline Target & CHARACTER \\
\hline obstacle & $\square$ \\
\hline Entersightrange & $\bar{\square}$ \\
\hline Facing Left & $\checkmark$ \\
\hline Facing Right & $\square$ \\
\hline
\end{tabular}

(c)

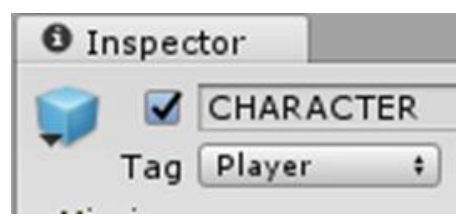

(b)

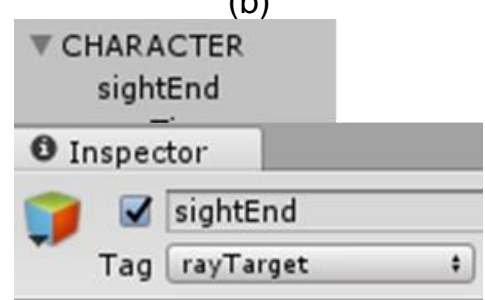

(d)

Figure 8. (a) Circle Collider2d, (b) Player Tag, (c) Sight Start on Boss Enemy, (d) Sight End on Character Player

Ray cast which is fired from a boss enemy towards the player can detect when there is an obstruction or obstacle that blocks the view of the boss enemy to the player. Ray cast will detect object that is on a specific layer like object tile/ground layer on the platform, when a player is within a point of view of the boss enemy then enter "sight range" indicator in Figure 9 will value

REPOSITOR, Vol. 1, No. 2, Desember 2019: 151-158 
true as well the opposite and indicators "obstacle" would be value true if there exists an object obstructing the view of the boss enemy as well as the opposite. The look of the application of the line of sight can be seen in Figure 10.

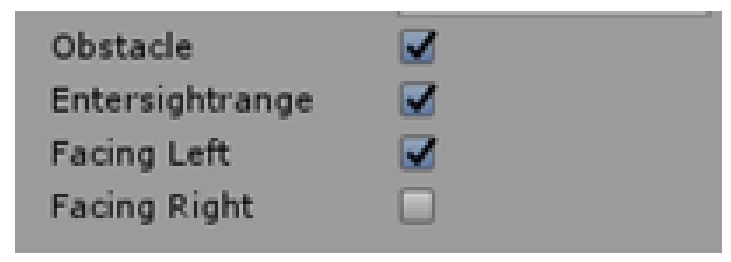

Figure 9 Indicators of Obstacle and Enter Sight Range

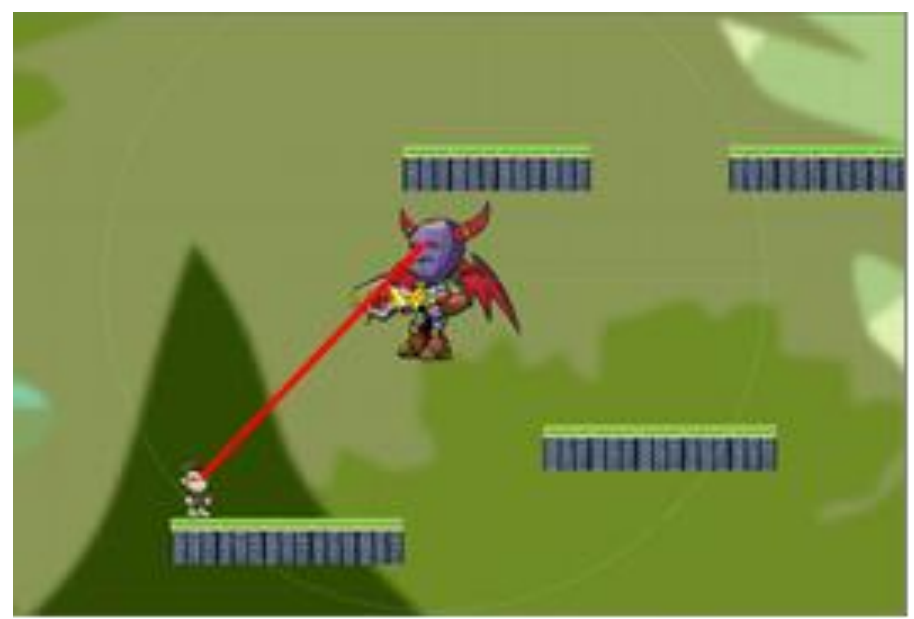

Figure 10. Application of Ray Cast on a Boss Enemy

\section{Results and Discussion}

\subsection{Scenario Testing}

Scenario testing [10] This is done to see if the line of sight algorithms applied to the Boss enemy is already running as expected. Can be seen in Table 1, as for the draft table behavior expected from a Boss enemy after applied the algorithm of line of sight, the observed points is the position of the player, whether the player is at a distance of view Boss enemy, whether the player is hindered by an obstacle can obstruct the view of the boss enemy behavior, and what will be done by the Boss enemy.

Table 1. Table Design Behavior Boss enemy

\begin{tabular}{ccccc}
\hline No. & Player position & $\begin{array}{c}\text { Player in } \\
\text { sight range }\end{array}$ & Obstacle & Behavior \\
\hline 1 & In front of Boss & No & No & Not attacking \\
2 & In front of Boss & No & Yes & Not attacking \\
3 & In front of Boss & Yes & No & Attacking \\
4 & In front of Boss & Yes & Yes & Not attacking \\
5 & Behind of Boss & No & No & Not attacking \\
6 & Behind of Boss & No & Yes & Not attacking \\
7 & Behind of Boss & Yes & No & Turn and attacking \\
8 & Behind of Boss & Yes & Yes & Not turning and not \\
\end{tabular}

\subsection{Boss Enemy Sight Range Testing}

On this testing it will involve as many as 5 people respondents, this test is used to find out the influence of the radius of the circle collider2d used as a boss enemy visibility. On Table 2 and Table 3, there are 5 categories of radius that are used in this test i.e. 3, 6, 9, 12 and 15, then let the respondents played 10 times for each category that aims to find out the average of victory and defeat after playing against boss enemy. 
Table 2. The Average of Victory

\begin{tabular}{cccccc}
\hline Criteria & \multicolumn{5}{c}{ The size of radius sight range } \\
\hline & 3 & 6 & 9 & 12 & 15 \\
\hline Average of win & 0.6 & 0.64 & 0.62 & 0.58 & 0.34 \\
\hline
\end{tabular}

Table 3. The Average of Defeat

\begin{tabular}{cccccc}
\hline Criteria & \multicolumn{5}{c}{ The size of radius sight range } \\
\hline & 3 & 6 & 9 & 12 & 15 \\
\hline Average of lose & 0.4 & 0.36 & 0.38 & 0.42 & 0.66 \\
\hline
\end{tabular}

After knowing the number of averages victory and defeat then the data will be converted into the form of a graph so that it can be known to the point of intersection of the level of victory and defeat. From the point of intersection of that, then we can figure out a large radius that can be used in this research. Average of winning and losing can be seen in Figure 11.

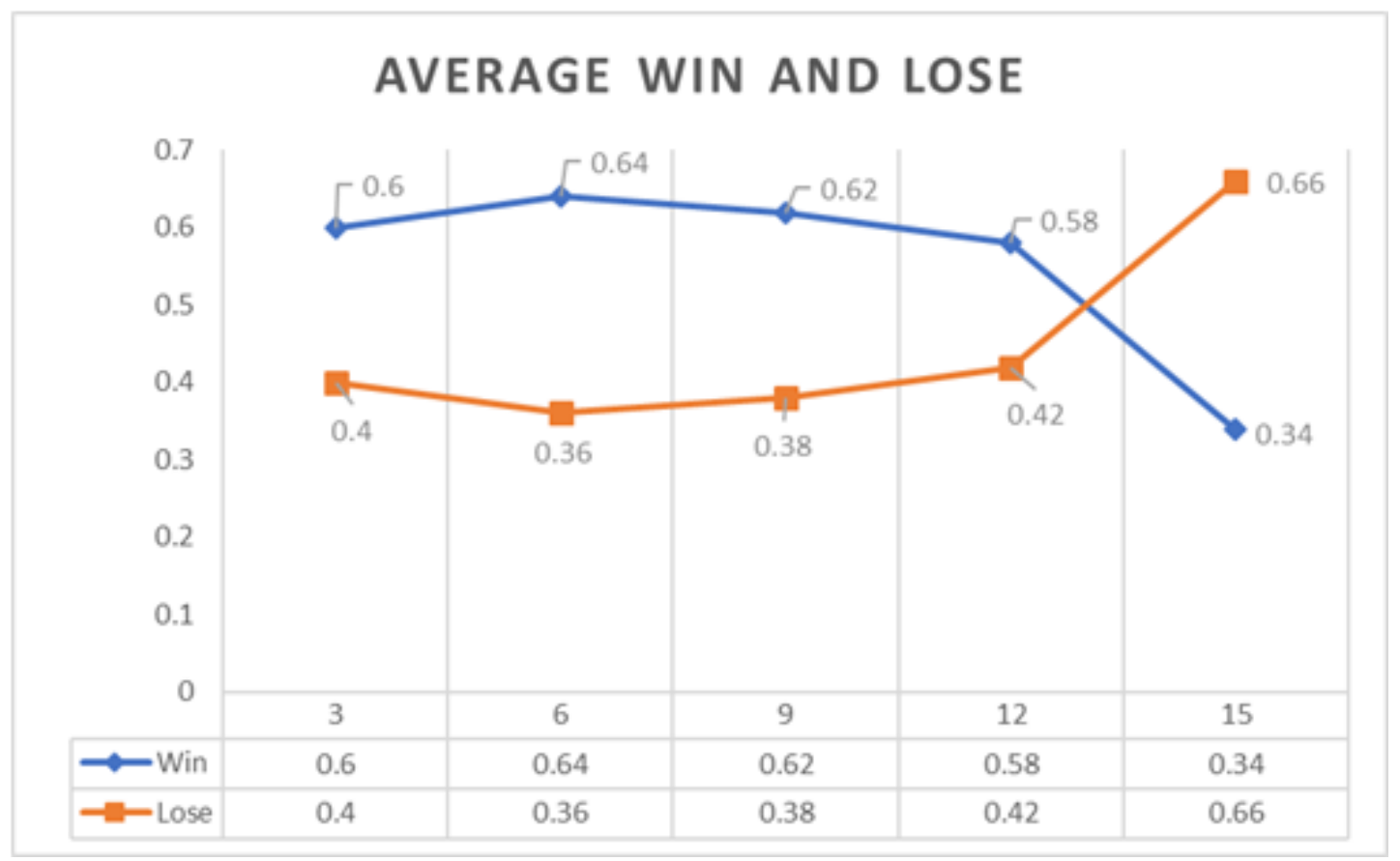

Figure 11. Graphs Average of Victory And Defeat

In Figure 11, the results averages of victory and defeat experienced the intersection between a radius of 12 and 15 . In this case then the level of victory and defeat at the point of intersection is balanced so that it can be applied to this research.

\subsection{Dynamic Game Balancing}

Dynamic Game Balancing test [11] divided into two, the first evaluation of the level of difficulty of the game against the respondent. This test is done in a manner involving 30 people conducted by way of introducing the Boss enemy in the game "Mystical Weapon of Nusantara" to respondent. Then let the respondents play the game for 5 minutes and play 20 times that aims to find out the average respondent won and lost against the Boss enemy and to know the average time required to complete the game. The next test respondents were given the questions in the questionnaire about the characteristics of play against the Boss enemy who aiming to find out the average desire respondents against characteristics of the Boss enemy, and last test as to whether game "Mystical Weapon of Nusantara" can be used as a media to introduce traditional weapon of Indonesia.

1. Evaluation the level of difficulty of the game

Evaluation the level of difficulty of the game made against the respondents is useful for mapping the status of the game. The data becomes the value that determines how easy or difficult for player to play it. Table 4 shows the overall results of the testing of the respondent.

REPOSITOR, Vol. 1, No. 2, Desember 2019: 151-158 
Table 4. The Results of the Overall Approach to Testing the Respondents

\begin{tabular}{|c|c|c|c|c|c|}
\hline \multirow{2}{*}{ No } & \multirow{2}{*}{ criteria } & \multicolumn{4}{|c|}{ Methods } \\
\hline & & \multicolumn{2}{|c|}{ Line of sight } & \multicolumn{2}{|c|}{ Normal } \\
\hline 1 & $\begin{array}{c}\text { The number of } \\
\text { won and lost }\end{array}$ & Win & lose & Win & Lose \\
\hline & Rata - rata & 0.63 & 0.37 & 0.323 & 0.677 \\
\hline
\end{tabular}

\begin{tabular}{cccc}
2 & Time to finish the & \multicolumn{2}{c}{ Methods } \\
\cline { 2 - 3 } & game & $\begin{array}{c}\text { Line of } \\
\text { sight }\end{array}$ & normal \\
\hline Rata - Rata & 174,467 & 137,067 \\
\hline
\end{tabular}

2. Characteristics of The Opponent

The statement detailed questionnaire is divided into 2 of the statement that is an interesting opponent is the opponent who can see the player, and an interesting opponent is the opponent who can be avoided. On Table 5, each statement will be filled by respondents with fill 1 of 5 answers allowed, namely:

$\begin{array}{lll}1 & = & \text { Strongly Disagree } \\ 2 & = & \text { Disagree } \\ 3 & = & \text { Neutral } \\ 4 & = & \text { Agree } \\ 5 & = & \text { Strongly Agree }\end{array}$

Table 5. The Test Results of the Opposing Game Characteristics

\begin{tabular}{lllllll}
\hline No & \multicolumn{1}{c}{ criteria } & 1 & 2 & 3 & 4 & 5 \\
\hline $1 . \quad \begin{array}{l}\text { an interesting opponent is the } \\
\text { opponent who can see the player }\end{array}$ & 0 & 7 & 7 & 12 & 4 \\
an interesting opponent is the & 2 & 1 & 12 & 12 & 3 \\
\hline
\end{tabular}

a) In Equation 1, an interesting opponent is the opponent who can see the player.

$$
\frac{(0 \times 1)+(7 \times 2)+(7 \times 3)+(12 \times 4)+(4 \times 5)}{30}=3.43
$$

b) In Equation 2, an interesting opponent is the opponent who can be avoided.

$$
\frac{(2 \times 1)+(1 \times 2)+(12 \times 3)+(12 \times 4)+(3 \times 5)}{30}=3.43
$$

3. Test as media introduction of the traditional weapons can be seen in Table 6.

Table 6. Results of Testing the Game Mystical Weapon of Nusantara as a Media Introduction to Traditional Weapons

\begin{tabular}{llllllll}
\hline No & \multicolumn{1}{c}{ criteria } & 1 & 2 & 3 & 4 & 5 \\
\hline 1 & $\begin{array}{l}\text { Does game "Mystical Weapon of } \\
\text { Nusantara" can be used as a media } \\
\text { introduction of the traditional } \\
\text { weapons Indonesia }\end{array}$ & 0 & 1 & 11 & 10 & 8 \\
\hline
\end{tabular}

a) In Equation 3, does game "Mystical Weapon of Nusantara" can be used as a media introduction of the traditional weapons Indonesia. 


\section{Conclusion}

From 3 test conducted, there are 5 statements that can be conducted. From the first test, all scenario achieve same value as the table of behavior design, it can be concluded the method line of sight is working properly. From the second test, sight range test, averages of victory and defeat experienced the intersection between a radius of 12 and 15 , it can be concluded then the level of victory and defeat at the point of intersection is balanced so that it can be applied to this research. From the third test, dynamic game balancing, the average winning using line of sight method is 0.63 it's higher than average winning without line of sight which is only 0.323 , it can be concluded the method can rise the winning rate. The following result from the third test is about characteristic of the opponent both have average of 3.43 which can be concluded if the respondents is accepting but in neutral side, it also apply for the last test about does game "Mystical Weapon of Nusantara "can be used as a media introduction of the traditional weapons Indonesia have average of 3.167.

\section{References}

[1] F. Fannani, L. Husniah, and A. S. Kholimi, "Perancangan Game 'Mystical Weapons Of Nusantara."

[2] P. L. Ekawati and A. Z. Falani, "Pemanfaatan Teknologi Game Untuk Pembelajaran Mengenal Ragam Budaya Indonesia Berbasis Android," vol. 22, no. 1, pp. 30-36, 2015.

[3] I. Millington and J. Funge, Artificial Intelligence for Games, Second Edition. 2009.

[4] S. Rabin, Game Al Pro, no. 35. 2014.

[5] E. Adams, Fundamentals of Game Design. 2013.

[6] C. W. Reynolds, "Steering behaviors for autonomous characters," Game Dev. Conf., pp. 763-782, 1999.

[7] UNITY, "Collider 2D." [Online]. Available: https://unity3d.com/learn/tutorials/topics/2d-gamecreation/collider-2d. [Accessed: 23-Oct-2017].

[8] UNITY, "Circle Collider 2D," 2017.2-001R. [Online]. Available: https://docs.unity3d.com/Manual/classCircleCollider2D.html?_ga=2.7505137.250379653.1508727767-1683130353.1505967661. [Accessed: 23-Oct-2017].

[9] UNITY, "Physics2D.Raycast," 5.6-0011. [Online]. Available: https://docs.unity3d.com/ScriptReference/Physics2D.Raycast.html. [Accessed: 28-Apr2017].

[10] C. Kaner, "An introduction to scenario testing," Cent. Softw. Test. Educ. Res., no. June, pp. $1-10,2003$.

[11] G. Andrade, G. Ramalho, A. Gomes, and V. Corruble, "Dynamic game balancing: An evaluation of user satisfaction," Proc. Second Artif. Intell. Interact. Digit. Entertain. Conf., pp. 3-8, 2006. 